\title{
Laser Auto Fluorescence and Dye-enhanced Spectroscopic Detection of Normal and Cancerous Human Lung Cell Lines and Plasmonic Photothermal Heating
}

\author{
Mohammad E Khosroshahi' ${ }^{1,2,3 *}$, Maral Asemani' ${ }^{1}$ and Payam Khoshkenar ${ }^{1,4}$ \\ ${ }^{1}$ Laser and Nanobiophotonics Laboratory, Faculty of Biomedical Engineering, Amirkabir University of Technology, Tehran, Iran \\ ${ }^{2}$ MIS-Electronics, Nanobiophotonics \& Biomedical Research Laboratory, Richmond Hill, Canada \\ ${ }^{3}$ Department of Mechanical and Industrial Engineering, University of Toronto, Toronto, Canada \\ ${ }^{4}$ University of Massachusetts Medical School, Worchester, USA
}

\section{Abstract}

This work describes the results of laser autofluorescence, dye-enhanced fluorescence spectroscopy of normal MRC-5 and cancerous QU-DB human lung cell lines and the effect of gold nanoshells heating on the cells. It was shown that the intensity ratio of MRC- 5 to QU-DB $80(\Delta R)$ and the shape factor $\left(R_{p}\right)$ can be appropriate indicators of normal and cancerous cells for primary and secondary peaks at $500 \mathrm{~nm}$ and $590 \mathrm{~nm}$ respectively. About $5 \mathrm{~nm}$ red shift was observed in the case of cancerous cells. Highest temperatures of about 51 and $39.5^{\circ} \mathrm{C}$ were achieved for (S3, S4) and $(\mathrm{S} 5, \mathrm{~S} 6)$ respectively. The percentage of damaged cells and nanoshells density are expected to decrease with radial distance from the center of the beam. The results also indicated an increasing degree of apoptosis with increasing the laser power, which critically governs the quality and the degree of laser-hyperthermia. The matrix temperature is thought to vary due to possible thermal overlapping of a larger fraction of NSs, agglomeration and clustering.
\end{abstract}

Keywords: Laser fluorescence; Lung cells; Cancer; Spectroscopy; Gold nanoshells; Photothermal

\section{Introduction}

Cancer as a major cause of death worldwide is characterized by an uncontrollable proliferation of cells which invades and spreads via the lymphatic system to distant parts of the body. More than six million people die from cancer and more than ten million are diagnosed with new cases every year worldwide [1,2]. Lung cancer is the most commonly occurring cancer in men and the third most commonly occurring cancer in women. There were two million new cases in 2018 and is the second highest in all cancers only behind prostate and breast [3]. Cancer originates from our tissues, complicating both diagnosis and treatment methods due to similarities between the normal and diseased tissue. Generally, lung cancer is mainly classifying as small cell lung cancer (SCLC-13\%) and non-small cell (NSCLC-87\%) carcinomas for their histology.

Despite this fact, the survival rate is much better if the tumor is detected at early stage particularly at in situ stage or minimally invasive without metastasis. While one of main objectives during cancer detection or screening and treatment is to help patient to have the minimum discomfort and anxiety, the main criteria for a given technique are considered:1-minimum risks, 2-reliability, 3-cost effectiveness, 4-acceptablity, 5-accuracy, and 6-effectiveness. The current clinical detection techniques of cancer are mainly a) traditional biopsy or tissue histopathology where morphological analysis of cells is performed for suspected diseased cells [4] and b) imaging systems including X-ray, mammography, computed tomography (CT), positron emission tomography (PET), single-photon emission computed tomography (SPECT), magnetic resonance imaging (MRI), ultrasound and optical where each technique has its inherent advantages and limitations in terms of sensitivity, resolution, radiation dose, ionizing radiation and ability to differentiate between normal and malignant lesions.

Laser-induced fluorescence spectroscopy (LIFS) is one of wellknown and most widely utilized optical spectroscopic methods which has received increasing attention due to its development of protocols for early diagnosis of various cancers because of its high sensitivity to changes in morphology, function and its conditions in cells as well as tissues [5-7]. In turn, these alterations from tissue are shown in the corresponding spectral characteristics. The subsequent relaxation to the ground electronic state occurs either radiatively as emission of photon i.e., fluorescence or non-radiatively as heat. In the former case, the output can be shifted to both longer (Stokes) or shorter (anti-Stokes) wavelengths [5-8]. The former is a characteristic of the biochemical composition of the biomaterials such as tissues which is utilized for cancer detection purpose [9]. A preclinical comparison of different optical imaging systems of spectroscopy, luminometry and digital imaging is reported by Judy et al. [7].

The fluorescence of natural substances or endogenous fluorophores governing the cellular fluorescence depending on the wavelengths include nicotinamide adenine dinucleotide (phosphate) $\mathrm{NAD}(\mathrm{P}) \mathrm{H}$, riboflavin (flavin mononucleotide FMN, flavin adenine dinucleotide (FAD), collagen, elastin, amino acids, vitamins, lipids, and porphyrins is called autofluorescence [10]. Fluorescence of FMN and FAD provide information regarding the metabolic changes in cells [11]. The fluorescence emission of tissue is normally studied in terms of signal intensity, spectral distribution and radiative lifetime. Thus, LIFS can differentiate both the alterations as tissue progress from a normal to diseased state and the endogenous fluorophores from exogenous

*Corresponding author: Mohammad E Khosroshahi, MIS-Electronics, Nanobiophotonics and Biomedical Research Laboratory, Richmond Hill, Canada, Tel: 14169781287; E-mail: khosrom@mie.utoronto.ca

Received: January 31, 2019; Accepted: February 19, 2019; Published: February 25, 2019

Citation: Khosroshahi ME, Asemani M, Khoshkenar P (2019) Laser Auto Fluorescence and Dye-enhanced Spectroscopic Detection of Normal and Cancerous Human Lung Cell Lines and Plasmonic Photothermal Heating Nanomed Nanotechnol 10: 525. doi: 10.4172/2157-7439.1000525

Copyright: (C) 2019 Khosroshahi ME, et al. This is an open-access article distributed under the terms of the Creative Commons Attribution License, which permits unrestricted use, distribution, and reproduction in any medium, provided the original author and source are credited. 
Citation: Khosroshahi ME, Asemani M, Khoshkenar P (2019) Laser Auto Fluorescence and Dye-enhanced Spectroscopic Detection of Normal and Cancerous Human Lung Cell Lines and Plasmonic Photothermal Heating. J Nanomed Nanotechnol 10: 525. doi: 10.4172/21577439.1000525

agents. The major advantages of LIFS for diagnosis include: safety, non-invasive, quantitative measurements, no need for biopsy hence histopathology, can be applied in real time and possibility of endoscopic optical fibre delivery for detection and imaging. LIFS can be performed in two different techniques of a) Steady-state (or time-integrated) and b) Time-dependent. In the former case, the measurements are used to characterize the biological tissues in terms of intensity, peak wavelengths and spectral shape. However, the main limitations of this approach may include relatively broad emission bands hence may reduce their discrimination ability of spectrally overlapping fluorophores, and influence of endogenous chromophores on the spectral profile. In the latter case, resolved fluorescence intensity decay provides some information about the lifetime and fluorescence dynamics of fluorophores. Despite such advantage, perhaps the major limitation of this approach in clinical implementation is its instrumentation complexity, time-consuming data acquisition and analysis and high cost of instrumentation. A comprehensive account is reported on the subject by Fang et al. [12].

The conventional treatments of cancers include surgical resection, chemotherapy, radiation therapy and targeted drug therapy but the advancement in engineered nanostructures during last decade has made the bioimaging, drug delivery and therapy significantly advantageous [13-18].

For example, plasmonic nanoshell-mediated laser hyperthermia is currently emerging as a novel approach of cancer therapy where the cancer cells are destroyed through laser-induced heating of on the surface or within the cells $[19,20]$. Basically, a nanoshell (NS) involves plasmon, which is basically a collective excitation or quantum plasma oscillation where the electrons simultaneously oscillate with respect to all the ions. They can be made tunable to different wavelengths by coating the dielectric core with different thickness of outer coating layer. Such nanoparticles exhibit strong optical absorption and scattering due to localized surface plasmon resonance (LSPR), which effectively increases the magnitude of the oscillations which in turn convert the light energy into heat. By tuning the absorption of NS to near infrared, where optical transmission through tissue is within the therapeutic window, a dose of heat can be produced and delivered to the site using moderately low exposures of laser radiation. From photothermal therapy prospective, which is based on the photosensitive agents aimed at localized destruction of cancer cells by conversion of near-infrared light into heat, the wavelength of maximal absorption and the absorption cross-section are key features to consider when selecting a particle for hyperthermia. Following our previous reports on LIFS $[6,21,22]$, we describe the results of steady state and dye-enhanced LIFS of human normal (MRC-5), cancerous (QU-DB) lung cancer cell lines using a low power $405 \mathrm{~nm}$ laser and the photothermal effects on cell lines containing gold NS irradiated by continuous $808 \mathrm{~nm}$ diode laser.

\section{Materials and Methods}

\section{Preparation of cell suspensions}

The procedure is similar to our previous report on osteosarcoma cell lines [6] where here human lung carcinoma cell lines (QU-DB 80, 165, 236,334 , NCBI-C565) and normal cell line of MRC-5, NCBI-C125) were purchased from national cell bank of Pasteur institute of Iran. Both the carcinoma and normal cell lines were grown in Dulbecco Modified Eagle Medium (DMEM, GIBCO 116-12800) with 1\% antibiotic Antimycotic Solution (PAA, P11-002). The carcinoma and normal cell lines were supplemented with $10 \%$ and $12 \%$ of Fetal Bovine Serum (FBS-GIBCO 106-10270) respectively as cell culture medium (C.C.M). The cells were then cultured in 96-well plates and grown in a humidified incubator at $37^{\circ} \mathrm{C}$ and $5 \% \mathrm{CO}_{2}$ until fully confluent. The cells were collected from culture flasks by standard trypsinization procedure, normally three days after passage when the cells have reached the confluence level, in order to yield a suspension. The suspension was then washed twice with phosphate-buffered saline (PBS-GIBCO 18912014). After washing, the cells were resuspended in $2 \mathrm{~mL}$ of $\mathrm{PBS}$ and pipetted into a cuvette with $1 \mathrm{~cm}$ path length for LIFS experiment. The cell concentration was determined by counting the number of cells per milliliter (cells/ $\mathrm{mL}$ ) using a haemocytometer from Neubauer chamber with a light microscope. The average cell viability was measured after $0.25 \%$ of Trypan Blue was added to PBS. The experiment was performed five times for each given cell sample for averaging the fluorescence output.

\section{Fluorescence spectroscopy}

The experimental setup is shown in Figure 1a where a $100-\mathrm{mW}$ laser pointer with $405 \mathrm{~nm}$ wave length (CSI-405, Germany) was used as an excitation source. The fluorescence was then suitably collected by a 600 $\mu \mathrm{m}$ core diameter with 0.22 numerical aperture optical cable (Ocean Optic 600-6-SR) which was then fed into spectrometer (Ocean Optic, UV-Vis USB2000-UK). Prior to experiments at room temperature, PBS was used as the reference spectrum. The results were then smoothed using Gaussian model FindGraph software. To determine the relative quantum yield, $10^{-2} \mathrm{mM}$ of fluorescein sodium powder (Merck, 518-478) was dissolved in water, stirred and filtered and used as a reference. For comparison of results, the $\mathrm{p}$ values were calculated by using the oneway analysis of variance (ANOVA) test. Each final data point represents an average of five readings. Statistically significant differences were considered as $p<0.05$. Figures $1 \mathrm{a}-\mathrm{c}$ illustrate the morphology and spreading of normal as negative control and carcinoma lung cells respectively using CCD camera (Panasonic Super Dynamic WVCP450-UK) connected to an optical microscope (Prior-UK) at 400 magnification. Clearly, the neighbouring MRC-5 cells maintained a physical contact with one another through multiple filament-type extensions while the QU-DB cells have an irregular and micro ridges type morphology.

\section{Photothermal heating of cell- gold nanoshell (Au NS)}

Photothermal treatment was performed using $85 \mathrm{~nm}$ synthesized gold coated $\mathrm{Fe}_{3} \mathrm{O}_{4} / \mathrm{SiO}_{2} \mathrm{NS}$ with an average shell thickness of $\sim 35 \mathrm{~nm}$ as described in our previous report [23]. For In-vitro assay, six groups of samples using QU-DB 80 cells were prepared. S1: (cells as control), S2 (cells exposed to laser), S3 (1 mL C.C.M + $0.1 \mathrm{mg} / \mathrm{mL}$ Au NS), S4 $(10 \mathrm{~mL}$ C.C.M $+0.1 \mathrm{mg} / \mathrm{mL}$ Au NS), S5 (1 mL C.C.M $+0.1 \mathrm{mg} / \mathrm{mL}$ Au NS + QU-DB cells) and S6 (10 mL C.C.M + $0.1 \mathrm{mg} / \mathrm{mL}$ Au NS + QU-DB cells). The samples were then exposed to laser radiation at 1 , 3,5 and $13 \mathrm{~W}$ respectively. The cell-NS medium was then irradiated by a home-made NIR diode laser at $808 \mathrm{~nm} \pm 10 \mathrm{~nm}$ with focal spot of 7 $\mathrm{mm}^{2}$ to evaluate the photothermal heating effect. The temperature was monitored by a digital thermometer with $0.1^{\circ} \mathrm{C}$ precision $(\mathrm{CHY} 502 \mathrm{~A} 1$, MULTI LOGGER) connected to laptop for further processing.

\section{Results}

Figure 2 illustrates the fluorescence of QU-DB cell lines between $\approx$ $420-650 \mathrm{~nm}$ with the primary peaks varying between 490 and $500 \mathrm{~nm}$ and the secondary between 585 and $590 \mathrm{~nm}$. Two points are noteworthy, first, the amplitude of fluorescence signal increases with increase of cell concentration per unit volume as it moves from QU-DB 80 to QU-DB 334 possibly because of more sensitive endogenous fluorophores at a given wavelength and secondly, the primary amplitudes are greater 
Citation: Khosroshahi ME, Asemani M, Khoshkenar P (2019) Laser Auto Fluorescence and Dye-enhanced Spectroscopic Detection of Normal and Cancerous Human Lung Cell Lines and Plasmonic Photothermal Heating. J Nanomed Nanotechnol 10: 525. doi: 10.4172/21577439.1000525

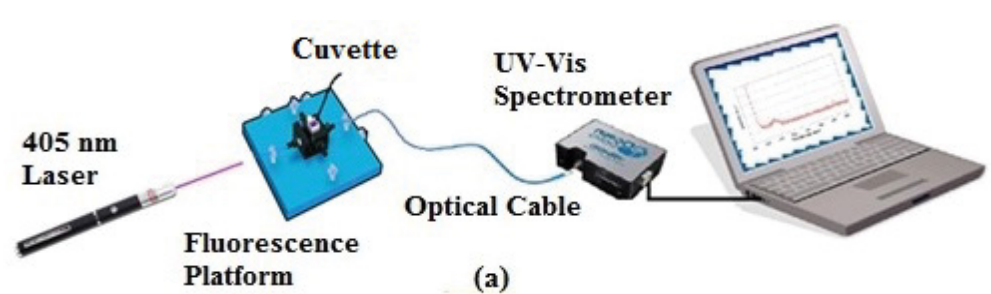

(b) MRC-5

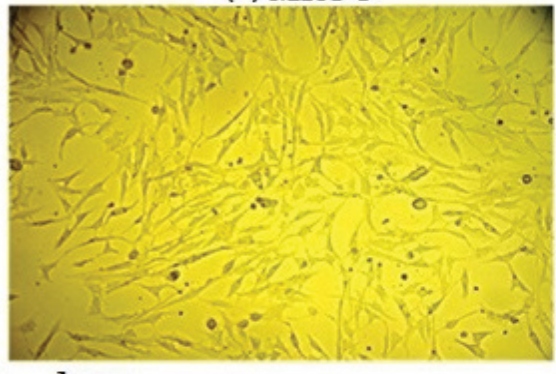

(c) QU-DB

$1 \mathrm{~mm}$

Figure 1: (a) Experimental setup, (b) microscopic image of normal lung cells (MRC-5) and (c) malignant QU-DB cells.
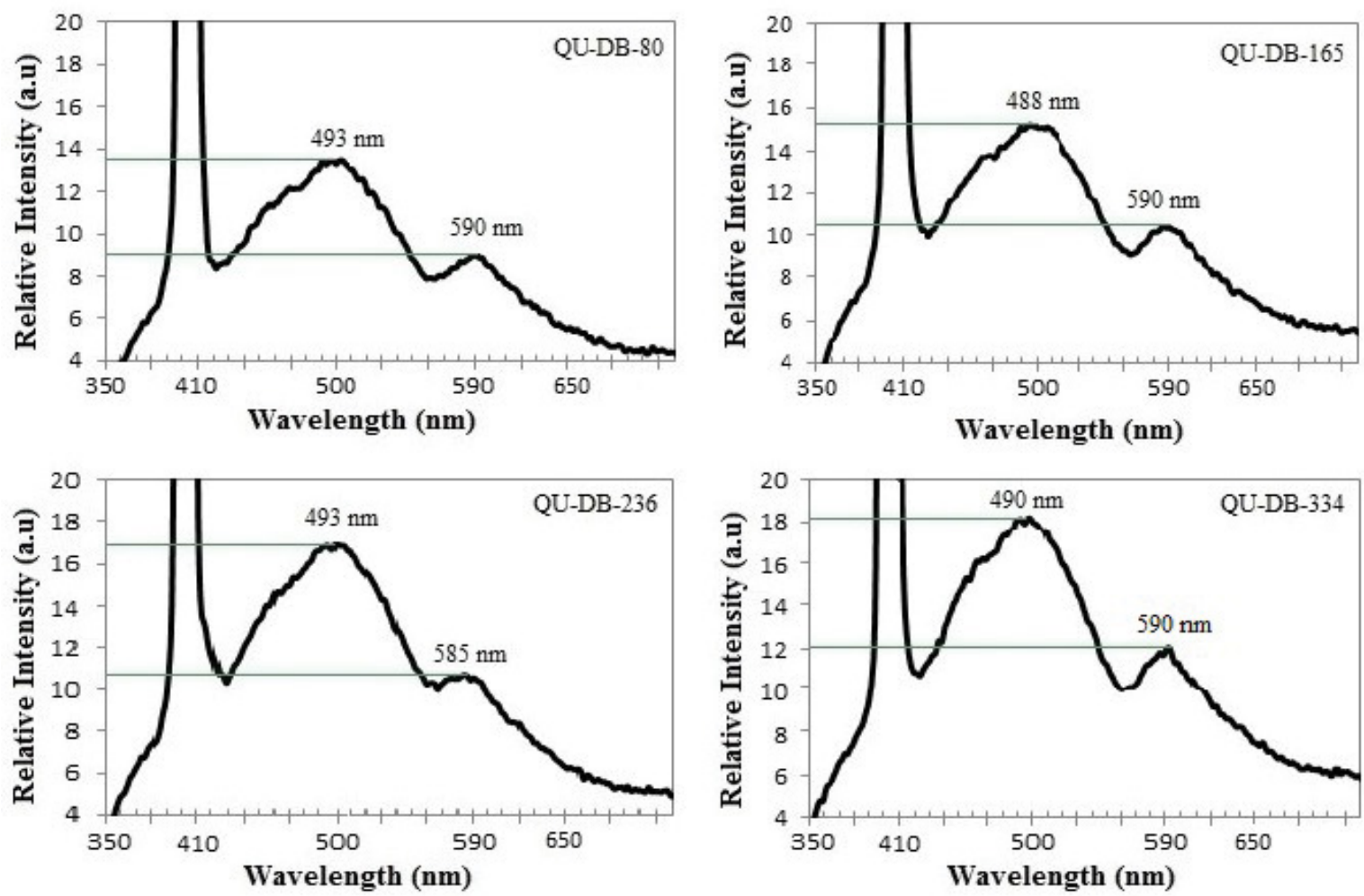

Figure 2: LIF relative intensity of malignant QU-DB lung cell lines. 
Citation: Khosroshahi ME, Asemani M, Khoshkenar P (2019) Laser Auto Fluorescence and Dye-enhanced Spectroscopic Detection of Normal and Cancerous Human Lung Cell Lines and Plasmonic Photothermal Heating. J Nanomed Nanotechnol 10: 525. doi: 10.4172/21577439.1000525

Page 4 of 13

than the secondary peaks. The highest intensity signals are observed with QU-DB 334 at 495 and $590 \mathrm{~nm}$ for primary and secondary peaks respectively. The differences in peaks can be explained in terms of biochemical and microstructural changes due to abnormalities. For example, the endogenous fluorophores responsible for a broad emission in the region of 480-500 $\mathrm{nm}$ are suggested to be NADH in both free and bound forms as well as FAD [24-27] and the broad emission between of $570-590 \mathrm{~nm}$ is attributed to presence of porphyrins $[24,28]$.

The average cell viability of $91.7 \pm 2 \%$ and $94.3 \pm 2 \%$ and cell concentrations of $9.2 \times 10^{5}$ and $\left(0.85 \times 10^{6}-3.34 \times 10^{6}\right)$ are determined for MRC-5 and QU-DB cell lines respectively as shown in Table 1. It was also shown that the viability of cells decreases by $10 \%$ after about 45 min fluorescence experiments [29].

Figure 3a indicates the relative fluorescence intensity of MRC-5 with one broad peak at about $500 \mathrm{~nm}$ and a minor peak at $585 \mathrm{~nm}$ and a similar result was obtained for QU-DB 80 with a significant decrease of intensity at both peaks with a red shift of about $5 \mathrm{~nm}$ at the secondary peak likely corresponding to changes in porphyrins fluorophores. Figure $3 \mathrm{~b}$ illustrates the variation of relative fluorescence intensity for MRC-5 and all four cancerous cell lines with cell concentration. MRC5 cells exhibited the highest intensity and in the case of cancerous, it gradually increased from lowest for QU-DB 80 to highest for QU-DB 334 respectively where it almost saturates probably because of increased turbidity of cells in suspension. Table 2 summarizes the above results including the intensity ratio of primary to secondary peak i.e., the shape factor $\left(\mathrm{R}_{\mathrm{p}}\right)$ and the dimensionless intensity ratio of normal to cancerous cells $(\Delta R)$ for both primary and the secondary peaks. As it is seen, the greatest ratio differential occurs between MRC-5 and QU-DB 80 with $\Delta \mathrm{R} \approx 1.49$ around $500 \mathrm{~nm}$ as the primary peak and $\Delta \mathrm{R} \approx 1.25$ at $585 \mathrm{~nm}$ for the secondary peak with approximately $5 \mathrm{~nm}$ red shift exhibited by cancerous cell lines.

As it is discussed in [6], an alternative to distinguish the normal and cancerous cells is to evaluate the area under the peak of fluorescence output signal, which is in an arbitrary unit and can be calculated for the main peak response of sample cells. This is done by using Find Graph software for MRC-5 and QU-DB 80 lines i.e., $\left(R s=\frac{S_{M R C-5}}{S_{Q u-D B 80}}\right)$ between 420 and $650 \mathrm{~nm}$ with the results of $\mathrm{Rs}=1.41$ and 1.06 corresponding to maximum and minimum values for QU-DB 80 and QU-DB 334 respectively. It is noted that Rs (MRC-5) is about 1.5 times of Rs (QU-DB 80 ) and that Rs $\approx 1.41>1$ is considered numerically meaningful as shown in Table 3 .

Figure $4 \mathrm{a}$ indicates the normalized laser induced-fluorescence spectra of MRC-5 and QU-DB 80 with no difference at $500 \mathrm{~nm}$ where the peaks overlap. The maximum difference occurs in the region $560-610 \mathrm{~nm}$ and the peak at $590 \mathrm{~nm}$ can be used as an indicator for carcinogenic cells. The normalized spectrum of QU-DB 80 with respect to MRC-5 is illustrated in Figure $4 \mathrm{~b}$ where the maximum difference is observed between $500-590 \mathrm{~nm}$.

Based on the intensity evaluation, the decrease in fluorescence peak would allow a clear discrimination between normal and cancerous cells. To overcome the limitations of numerical intensity measurements, $R_{p}=$ $\mathrm{I}_{500} / \mathrm{I}_{590}$ is considered as normalized value for MRC-5 and QU-DB 80 cell lines in each case. Thus, the values of $\Delta \mathrm{R} \approx 1.71$ and 1.58 given in Table 4 appears to be an appropriate indicator for primary and secondary at 500 $\mathrm{nm}$ and $590 \mathrm{~nm}$ respectively. The fact that both intensities are influenced

\begin{tabular}{|c|c|c|}
\hline Cell Sample & Cell Concentration (Cell/mL) $\pm \mathbf{1 0} \%$ & $9.2 \times 10^{5}$ \\
\hline MRC-5 & $0.85 \times 10^{6}$ \\
\hline QU-DB 80 & $1.65 \times 10^{6}$ \\
\hline QU-DB 165 & $2.36 \times 10^{6}$ \\
\hline QU-DB 236 & $3.34 \times 10^{6}$ \\
\hline QU-DB 334 & $94.3 \pm 3$ \\
\hline
\end{tabular}

Table 1: The average cell viability of MRC-5 and QU-DB cells prior to LIFS experiment.
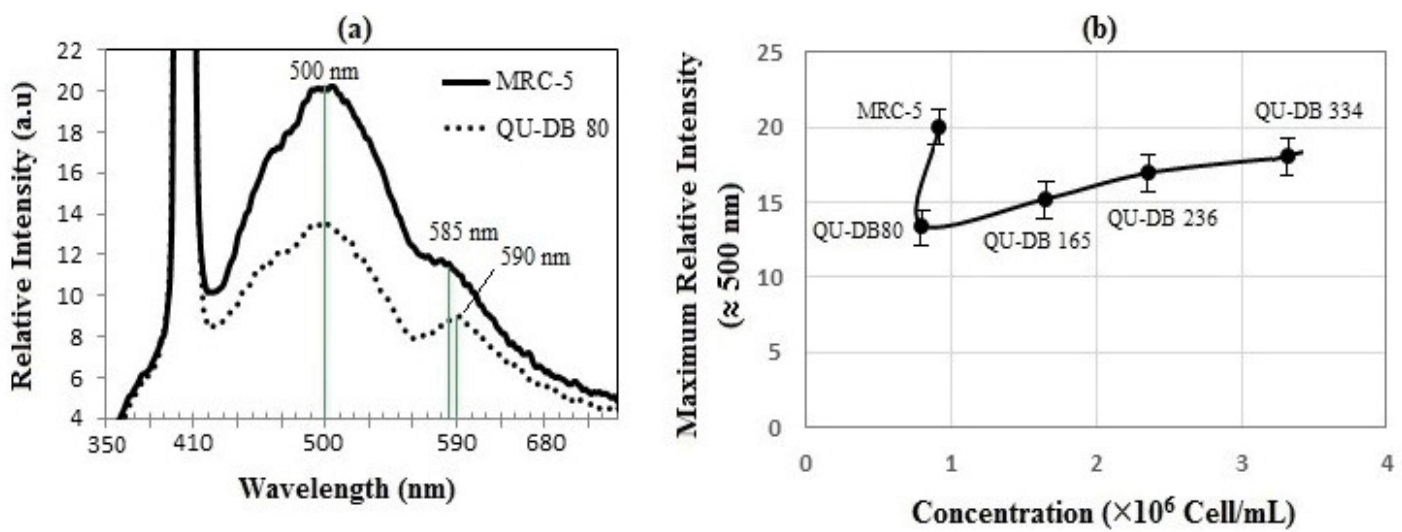

Figure 3: (a) LIF relative intensity of MRC- 5 and carcinoma QU-DB-80 cells. The primary and secondary peaks are observed at 500 and 585 nm respectively for MRC- 5 with $5 \mathrm{~nm}$ red-shift for the secondary peak of QU-DB-80 cells and (b) variation of relative intensity signal with cell concentration of MRC- 5 and QU-DB-80 cells. 
Citation: Khosroshahi ME, Asemani M, Khoshkenar P (2019) Laser Auto Fluorescence and Dye-enhanced Spectroscopic Detection of Normal and Cancerous Human Lung Cell Lines and Plasmonic Photothermal Heating. J Nanomed Nanotechnol 10: 525. doi: 10.4172/21577439.1000525

Page 5 of 13

\begin{tabular}{|c|c|c|c|}
\hline Cell Sample & $I_{1 \max }$ (Primary) & $I_{2 \max }($ Secondary) & $R p=I_{1} / I_{2}$ \\
\hline QU-DB 80 & 13.50 & 9.0 & 1.50 \\
\hline QU-DB 165 & 15.20 & 10.20 & 1.49 \\
\hline QU-DB 236 & 16.85 & 10.95 & 1.54 \\
\hline QU-DB 334 & 18.10 & 12.01 & 1.51 \\
\hline MRC-5 & 20.20 & 11.30 & 1.78 \\
\hline \multicolumn{2}{|c|}{$\Delta \mathrm{R}=\mathrm{I}_{\mathrm{MRC}-5} / \mathrm{I}_{\mathrm{QU}-\mathrm{DB}}($ Primary $)$} & \multicolumn{2}{|c|}{$\Delta R=I_{\mathrm{MRC}-5} / I_{\mathrm{QU}-\mathrm{DB}}($ Secondary $)$} \\
\hline \multicolumn{2}{|c|}{1.49} & \multicolumn{2}{|c|}{1.25} \\
\hline \multicolumn{2}{|c|}{1.32} & \multicolumn{2}{|c|}{1.10} \\
\hline \multicolumn{2}{|c|}{1.19} & \multicolumn{2}{|c|}{1.03} \\
\hline \multicolumn{2}{|c|}{1.11} & \multicolumn{2}{|c|}{0.94} \\
\hline \multicolumn{2}{|c|}{--} & \multicolumn{2}{|c|}{--} \\
\hline
\end{tabular}

Table 2: Relative peak intensity and the ratio $(\triangle R)$ of MRC-5 to QU-DB fluorescence intensity.

\begin{tabular}{|c|c|c|}
\hline Cell Sample & $S=\int_{x 1}^{x 2} y d x,\left(x_{1}=420 n m, x_{2}=650 n m\right)$ & \\
\hline MRC-5 & $\left.R s=\frac{S_{M R C-5}}{S_{Q U-D B}}\right)$ & 3142.31 \\
\hline QU-DB 80 & 2234.47 & 1.41 \\
\hline QU-DB 165 & 2582.63 & 1.20 \\
\hline QU-DB 236 & 2782.76 & 1.13 \\
\hline QU-DB 334 & 2950.24 & 1.06 \\
\hline
\end{tabular}

Table 3: The integral or the area under the fluorescence curve of MRC- 5 and QU-DB cells and the ratio of the area under fluorescence peak of MRC-5 to QU-DB cells.

(a)

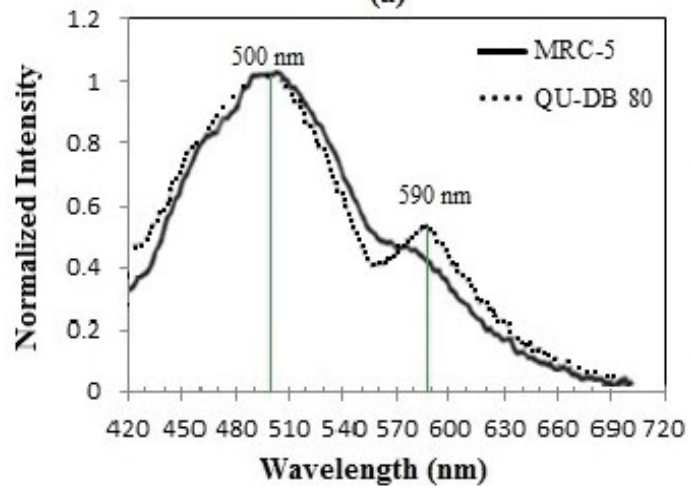

(b)

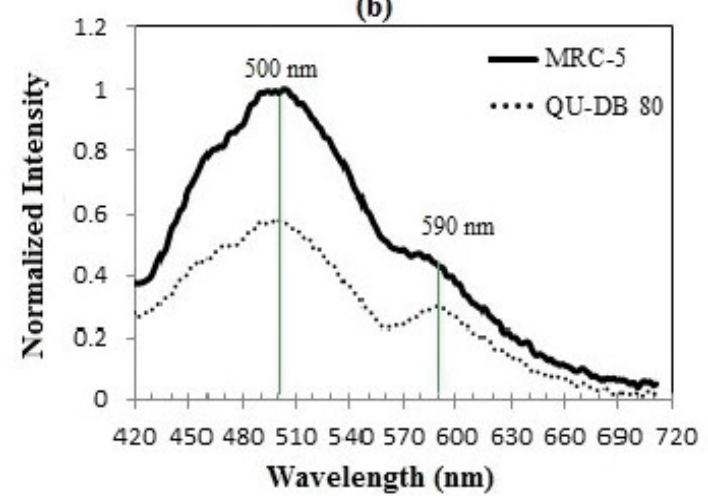

Figure 4: (a) Normalized fluorescence spectra of MRC-5 and QU-DB-80 cell lines and (b) normalized spectrum of MRC-5 cells with respect to QU-DB-80 cells with peaks at 500 and $590 \mathrm{~nm}$.

\begin{tabular}{|c|c|c|c|c|}
\hline Cell Sample & $I_{\max }(\sim 500 \mathrm{~nm})$ & $\left.I_{\max }(\sim 590) \mathrm{nm}\right)$ & $\mathrm{Rp}=\mathrm{I}_{500} / \mathrm{I}_{590}$ & $\Delta R=\mathrm{I}_{\text {MRC-5 }} / \mathrm{I}_{\text {QU-DB } 80}$ \\
\hline QU-DB 80 & 0.582 & 0.285 & 2.04 & 1.71 \\
\hline MRC-5 & 0.995 & 0.451 & 2.21 & 1.58 \\
\hline
\end{tabular}

Table 4: The shape factor of normalized spectra of MRC-5 and QU-DB cells and the ratio $(\Delta R)$ of normalized spectra of MRC-5 to QU-DB cells.

by experimental parameters indicates the very distinct shape of normal and cancerous cells spectra. A major advantage of this ratio is that the difference in intensity ratio at these wavelengths can be attributed to the difference in the fluorescence yield of the native fluorophores such as (i.e., NADH and riboflavin) for various cell types (Figure 5).

Similarly, the calculated values of area under the curve and the ratio of MRC-5 fluorescence signal to QU-DB 80 of normalized spectra (Rs) shown in Figure 4 are given in Table 5. The integral value of the normal cells increases such that the difference is significant compared to cancerous cells and that Rs (MRC-5) is about 1.7 times that of QUDB 80.
The next step is to calculate the quantum yield, $\eta$ i.e., the efficiency of emission where the fluorescence intensity of sample under study is compared to the intensity of a dye of known quantum yield as standard solution, which in our case, $10^{-2} \mathrm{nM}$ of fluorescein sodium (NaF$\mathrm{C}_{20} \mathrm{H}_{10} \mathrm{Na}_{2} \mathrm{O}_{5}$ ) with $\mathrm{q} \approx 0.79 \pm 0.06[6,30]$ was used as a reference. The $\mathrm{NaF}$ spectral emission between $500-600 \mathrm{~nm}$ with maximum peak at 525 $\mathrm{nm}$ is seen in Figure 5a. By comparing the fluorescence intensity of sample under study to that of the $\mathrm{NaF}$ and using the relation (1), one can calculate the fluorescence of unknown sample, $\mathrm{F}_{\mathrm{X}}$, 6 ]

$$
\frac{F_{x}}{F_{s}}=\frac{\eta_{x} I_{E} \% A_{x} G(\theta) x}{\eta_{s} Q I_{S} \% A_{s} G(\theta) s}
$$


Citation: Khosroshahi ME, Asemani M, Khoshkenar P (2019) Laser Auto Fluorescence and Dye-enhanced Spectroscopic Detection of Normal and Cancerous Human Lung Cell Lines and Plasmonic Photothermal Heating. J Nanomed Nanotechnol 10: 525. doi: 10.4172/21577439.1000525

(a)

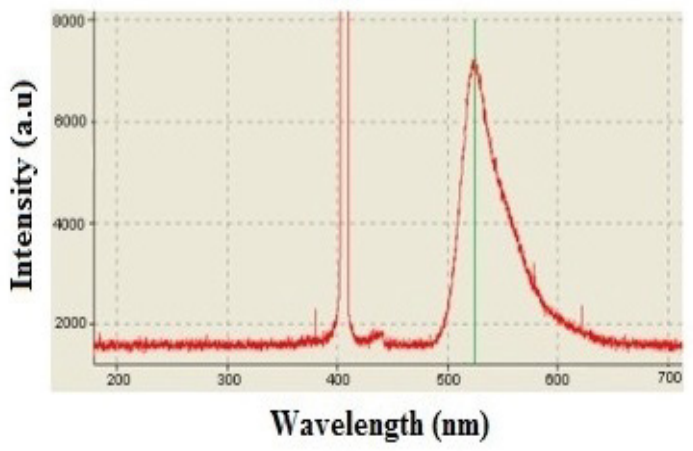

(b)

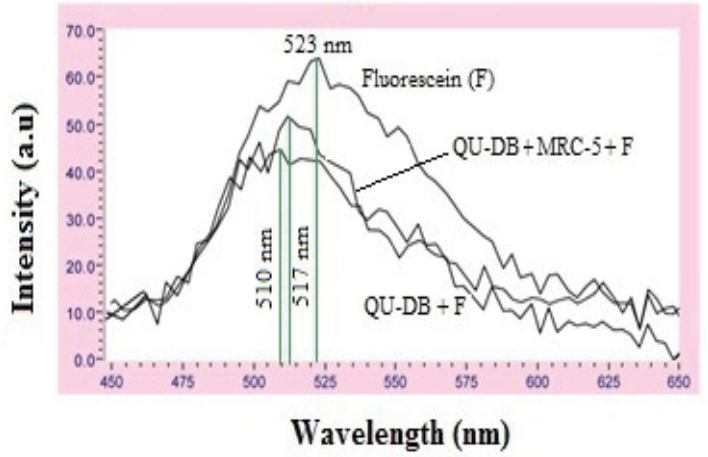

Figure 5: (a) Fluorescence spectrum of fluorescein sodium with a peak at around $520 \mathrm{~nm}$ and (b) comparison of LIF spectra of fluorescein, fluorescein with MRC-5, and fluorescein with QU-DB-80.

\begin{tabular}{|c|c|}
\hline & $S=\int_{x 1}^{x 2} y d x,\left(x_{1}=420, x_{2}=650\right)$ \\
\hline QU-DB 80 & 79.15 \\
\hline MRC-5 & 135.65 \\
\hline$R_{S}=\frac{S_{M R C-5}}{S_{Q U-D B-80}}$ & 1.71 \\
\hline
\end{tabular}

Table 5: Area under the curve and the ratio of normalized area of MRC-5 to QU-DB cells (Rs).

where $\mathrm{Fs}$ is the fluorescence of $\mathrm{NaF}$ solution, $\eta_{\mathrm{x}}$ and $\eta_{\mathrm{s}}$ are the quantum yield of known and $\mathrm{NaF}$ solution, $\mathrm{I}_{\mathrm{F}}$ is the intensity of exciting light, $\%$ As and $\% \mathrm{Ax}$ are the absorption percentage of solution $(100-\% \mathrm{~T}), \mathrm{G}(\theta)$ s and $\mathrm{G}(\theta) \mathrm{x}$ are geometry factor of $\mathrm{NaF}$ and measured fluorescence of known sample $(<1)$. Therefore, by exciting both samples at the same wavelength we have

$$
\frac{I_{E} \% A_{x} G(\theta) x}{I_{S} \% A_{S} G(\theta) S}=1
$$

Thus, giving the ratio of $\eta$ as

$$
\frac{F_{x}}{F_{s}}=\frac{\eta_{x}}{\eta_{s}}
$$

One aspect of fluorescence spectroscopy is to determine the light absorption and extinction coefficients using Beer-Lambert law,

$$
\log \frac{I o}{I}=\varepsilon c d
$$

Where $\mathrm{I}_{0}$ and $\mathrm{I}$ are the initial and exit intensity, $\varepsilon$ is the molar extinction coefficient and $d$ is the optical path. Assuming $10 \%$ light absorption for normal cells (i.e., $\mathrm{I}_{\mathrm{A}}=0.1 \mathrm{I}_{0}$ ) and $15 \%$ for cancerous cell suspension (i.e., $\mathrm{I}_{\mathrm{A}}=0.15 \mathrm{I}_{0}$ ), $\varepsilon$ can be calculated using equation (4). Therefore,

$$
\text { MRC-5: } \mathrm{c}=\varepsilon \times 9.2 \times 10^{5} \times 10^{-3} \times 1 \text { giving } \varepsilon \approx 5 \times 10^{-5}\left(\mathrm{~cm}^{2} \text {. cell }{ }^{-1}\right)
$$$$
\text { QU-DB: } c=\varepsilon \times 8.5 \times 10^{5} \times 10^{-3} \times 1 \text { giving } \varepsilon \approx 8 \times 10^{-5}\left(\mathrm{~cm}^{2}\right. \text {. cell-1) }
$$

Table 6 denotes the $\eta$ values for MRC- 5 and QU-DB cell lines where in cancerous cells, QU-DB 334 and QU-DB 80 showed the highest and lowest values respectively.
To investigate the effect of dye on autofluorescence response, MRC- 5 and QU-DB 80 cell lines were labelled by $1 \mathrm{mM}$ of NaF. As seen from the results in Figure $5 b$, there is a significant difference in the arbitrary intensity between MRC- 5 and QU-DB80 cells with $\approx 7$ nm of red shift.

Figure 6a shows the magnetization curve of the $\mathrm{Fe}_{3} \mathrm{O}_{4} / \mathrm{SiO}_{2} / \mathrm{Au}$ nanostructures at the room-temperature where the hysteresis loop shows a reversible behaviour implying that the magnetization, Ms curve exhibits zero remanence and coercivity. The Ms value for these nanostructures is $1.3 \mathrm{emu} \mathrm{g}^{-1}$, which is about $1.5 \%$ of the $\mathrm{Ms}$ for $\mathrm{Fe}_{3} \mathrm{O}_{4}$. Thus, the decrease in Ms is most likely the result of a large volume of $\mathrm{SiO}_{2} / \mathrm{Au}$. When the external magnetic field (1000 Oe) was removed, the particles redispersed rapidly i.e. the curve passing through the origin and this relatively fast magnetic response can be an advantage in many applications. An AFM example of Au NS and its 3-D images are respectively shown in Figures $6 \mathrm{~b}$ and $6 \mathrm{c}$. The size of the NS was determined $\approx 85 \mathrm{~nm}$ with $\approx 35 \mathrm{~nm}$ shell thickness using SPM software. These images provided useful information about surface topography and the size of gold nanoparticles with well-defined clarity, which effectively is correlated to optical absorption spectra.

The examples of photothermal treatment of cancer cells without Au NS at different power of 1, 3, 5 and $13 \mathrm{~W}$ irradiated for $180 \mathrm{~s}$ are given in Figure 7 where the colour of cells became slightly darker with increasing the laser power but overall no significant change in cell morphology was observed.

The results of laser irradiation of S3 and S4 at room temperature $(\approx$ $25^{\circ} \mathrm{C}$ ) are considered as base line i.e., the body temperature which are demonstrated in Figure $8 \mathrm{a}$ and $8 \mathrm{~b}$ where the temperature increases to $40{ }^{\circ} \mathrm{C}$ at $1 \mathrm{~W}$ and to $51{ }^{\circ} \mathrm{C}$ at $13 \mathrm{~W}$ without any significant difference in each concentration at given power. However, when the QU-DB cells 
Citation: Khosroshahi ME, Asemani M, Khoshkenar P (2019) Laser Auto Fluorescence and Dye-enhanced Spectroscopic Detection of Normal and Cancerous Human Lung Cell Lines and Plasmonic Photothermal Heating. J Nanomed Nanotechnol 10: 525. doi: 10.4172/21577439.1000525

Page 7 of 13

\begin{tabular}{|c|c|c|c|}
\hline Cell Sample & $\mathrm{A}_{\mathrm{x}}(440-550 \mathrm{~nm})$ & $\eta_{X}=\frac{A_{X} \eta_{S}}{A_{S}(550-650 \mathrm{~nm})}$ & $\%$ \\
\hline QU-DB 80 & 1296.28 & $\eta_{163}=\frac{1480.82 \times 0.79}{46487.6}=0.025$ & 2.2 \\
\hline QU-DB 165 & 1480.82 & $\eta_{163}=\frac{1480.82 \times 0.79}{46487.6}=0.025$ & 2.5 \\
\hline QU-DB 236 & 1637.95 & $\eta_{236}=\frac{1637.95 \times 0.79}{46487.6}=0.028$ & 2.8 \\
\hline QU-DB 334 & 1719.34 & $\eta_{334}=\frac{1719.34 \times 0.79}{46487.6}=0.029$ & 2.9 \\
\hline MRC-5 & 1932.47 & $\eta_{M R C-5}=\frac{1932.47 \times 0.79}{46487.6}=0.032$ & 3.2 \\
\hline
\end{tabular}

Table 6: The efficiency of MRC-5 and QU-DB cells.

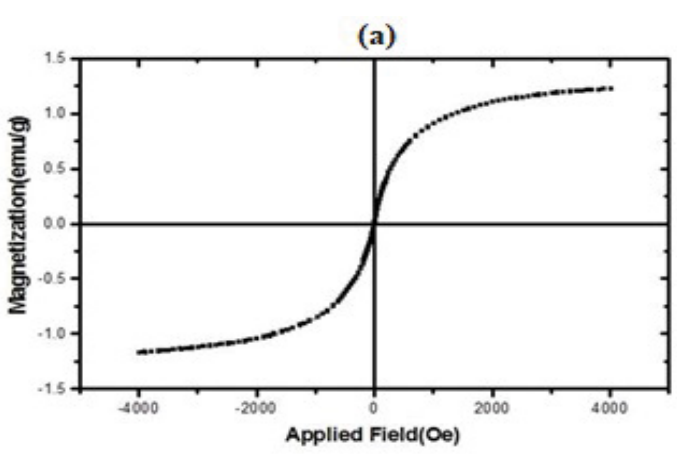

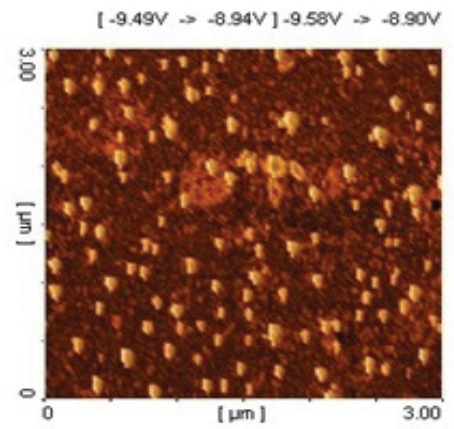

(b)
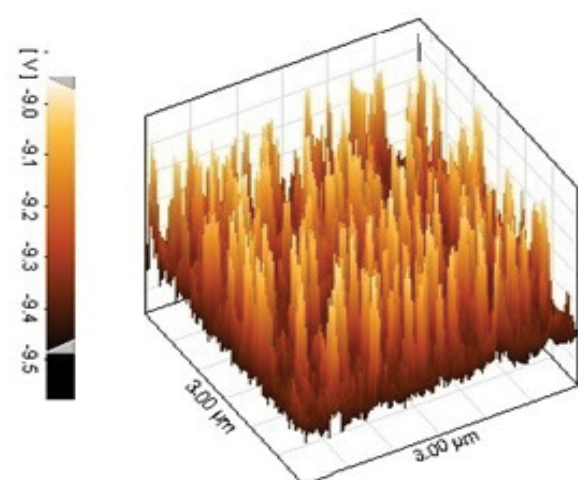

(c)

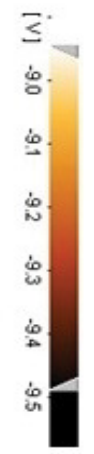

Figure 6: Variation of Au-NS magnetization with applied field and (b) 2-D and 3-D AFM photographs of surface topography of Au-NS.

were added, i.e., S5 and S6 as shown in Figure 8c and 8d respectively, the temperature decreased considerably down to about 37.5 and 40.5 ${ }^{\circ} \mathrm{C}$ at 1 and $13 \mathrm{~W}$ respectively. This is likely attributed to the protein adsorption, i.e., Vroman's effect in the presence of cells. In the cases of S3 and S4 (Figure 8e), the temperature increases linearly with power up to $\approx 10 \mathrm{~W}$ where there onwards, the curve begins to deviate from linearity. Similarly, for S5 and S6 (Figure 8e), the temperature increases linearly up to $4 \mathrm{~W}$ where a turning point is reached, and it remained constant. Clearly, the presence of cells reduces the temperature compared to S3 and S4.

Figure 9 demonstrates the cellular morphology changes for S5 irradiated at 1, 3, 5 and $13 \mathrm{~W}$ for one minute. The extend of thermal damage increases with increasing power due to heat transfer which will be discussed in next section. Similar results were obtained for S6 as shown in Figure 9 except with a lower degree of thermal damage.

A numerical simulation was performed to study the temperature distribution in $\mathrm{Au}$ NS, cells and combined Au NS and cells using 2D-Fourier and non-Fourier heat transfer models and to compare with the experimental results. As demonstrated, the results of non-Fourier simulation shown in Figure 10 is closer to experimental results than Fourier model particularly for S3 and S5.

\section{Discussion}

It is known that spectroscopy of native fluorophores are sensitive to parameters such as $\mathrm{pH}$, redox potential, ion concentration, polarity, 
Citation: Khosroshahi ME, Asemani M, Khoshkenar P (2019) Laser Auto Fluorescence and Dye-enhanced Spectroscopic Detection of Normal and Cancerous Human Lung Cell Lines and Plasmonic Photothermal Heating. J Nanomed Nanotechnol 10: 525. doi: 10.4172/21577439.1000525

Page 8 of 13

(a)

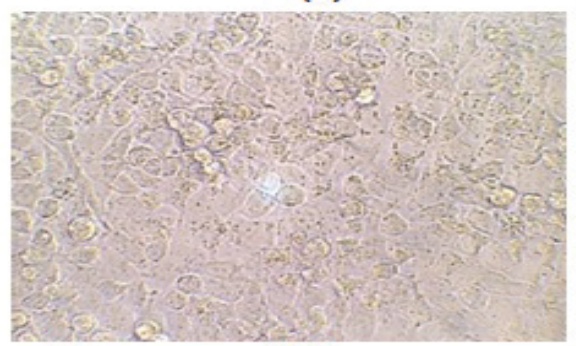

$\times 400$

$1 \mathbf{W}$

(c)

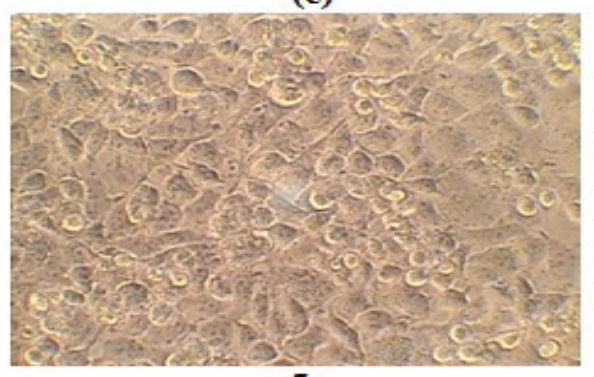

5 (b)

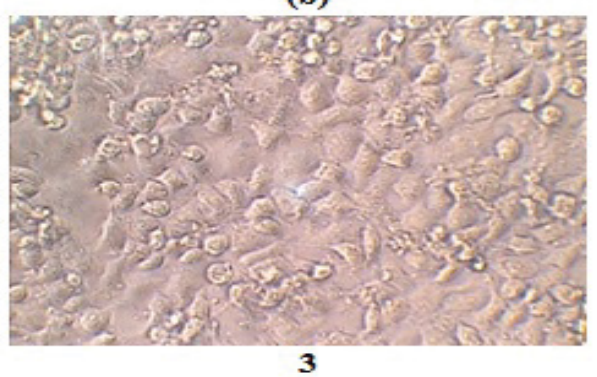

(d)

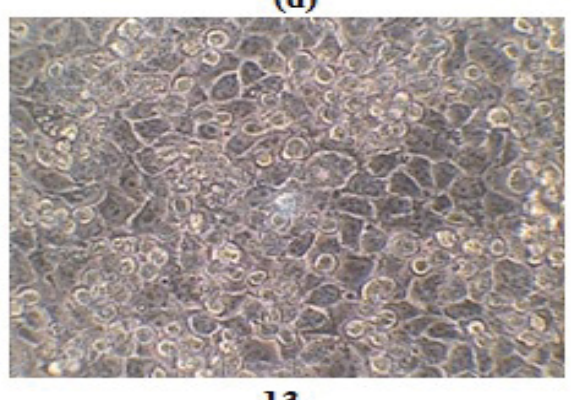

13

Figure 7: Optical microscope images of QU-DB-80 after irradiation for $180 \mathrm{~s}$ without NS at (a) $1 \mathrm{~W}$, (b) $3 \mathrm{~W}$, (c) $5 \mathrm{~W}$ and (d) $13 \mathrm{~W}$. The morphological changes are seen as shrinkage of cells undergoing apoptosis. The heating effect increases with increasing power due to thermal stress.

etc. For example, flavins fluoresce and shows spectral changes when transforming from the oxidized to reduced state [5]. The decrease of lung cancer peaks compared to normal cells, as in this case, is mainly due to deficiency of the aerobic oxidation as coenzyme NADH. When for some reasons the cancerous cells proliferate, the ratio between the non-fluorescent oxidized $\left(\mathrm{NAD}^{+}\right)$and the fluorescent reduced form $(\mathrm{NADH})$ of NAD alters and accumulation of $\mathrm{NAD}^{+}$with less fluorescence results in the decreased fluorescence in malignant cells [25]. It is shown that significant decrease in green autofluorescence intensity of tumor areas compared with normal bronchial tissue occurs $[31,32]$. Such a decrease was explained in terms of reduced amount of oxidized riboflavins in the lung cancer tissues.

In this case a Stokes shift was observed, which is a measure of relaxation process occurring in the excited state populated by absorption. As expected, the intensity of autofluorescence of all cancerous cells was less than the normal cells and a red shift of about $5 \mathrm{~nm}$ due to changes in biochemical structure of cells was observed. In most biological tissues, $\pi-\pi^{\star}$ transitions are more probable due to association of double bonds such as $\mathrm{C}=\mathrm{C}$ or $\mathrm{C}=\mathrm{O}$ with relatively high molar extinction coefficients. The use of exogenous fluorophores such as dye can enhance the $\Delta \mathrm{R}$ by accumulating preferentially in malignant tissues or cells. Thus, changes observed in fluorescence spectrum can be attributed to alterations in in number of factors including chromophore density, the physical structure and chemical composition during the tissue change of state. These changes consequently affect the optical properties of the tissue or cells which manifests itself as changes in amplitude, position and shift of fluorescence wavelengths. Also, the fluorescence intensities differ across all emission wavelengths for each spectrum shown and it is evident that the number of photons increases as the fluorescence wavelength increases (hence decrease of photon energy). This was also demonstrated by our previous reports on fluorescence spectroscopy and microscopy of L 929 and MCF-7 breast cancer cell lines [22,31].

The effect of NIR laser-induced apoptosis and hyperthermic treatment using Au NS was evaluated according to changes observed in cell morphology. Living QU-DB cells have fibroblast-like morphology while damaged cells shrink and have rounded shape [33]. The molecular effectors during the hyperthermia are cell membrane, cytoskeleton, intracellular proteins, nucleic acid and mitochondrial function. The results demonstrated the shrinkage of cells in response to heat stress due to disaggregation of the cytoskeleton after hyperthermia [33-35]. The main cause of cell death is thought because of changes in the cell membrane such as altered membrane fluidity, permeability and surface blobbing [36]. These changes may become evident during the recovery phase of the cell to the base-line temperature, but not immediately after heating [37]. Cells suffering apoptosis tend to shrink and hence exhibit cytoplasmonic and chromatin condensation where in the final stages the cells are divided into smaller apoptotic bodies [38]. Heat generated by absorption of incident photons is reradiated by NS as ohmic heat loss into the surrounding medium. Since, the diameter of NS, $\mathrm{D}_{\mathrm{P}} \approx 42.5$ $\mathrm{nm}<<\lambda \approx 810 \mathrm{~nm}$ and the geometry factor $\mathrm{x}=2 \pi \mathrm{R}_{\mathrm{p}} / \lambda \approx 0.33<<1$, Rayleigh scattering is applied and the particle is subject to a uniform electric field, which oscillates like a simple dipole with polarization proportional to the incident field. The complex refractive index, $\tilde{n}(\omega)$ of NS is related to its complex dielectric permittivity $\varepsilon_{\mathrm{p}}=\varepsilon_{\mathrm{r}}+\mathrm{i} \varepsilon_{\mathrm{i}}$ through $\varepsilon_{\mathrm{p}}=\tilde{n}^{2}=\left(\mathrm{n}_{\mathrm{r}}+\mathrm{ik} \mathrm{e}^{2}\right)^{2}$ where $\mathrm{n}_{\mathrm{r}}$ is the real part of the refractive index of embedding medium and $k_{e}(\lambda)=\lambda \alpha_{p} / 4 \Pi$ is extinction coefficient which determines the degree to which the metal polarizes in response to an applied external electric field, that is, it determines the SPR spectral peak position and is maximum when $\varepsilon_{\mathrm{p}}+2 \varepsilon_{\mathrm{m}}=0$ where $\varepsilon_{\mathrm{p}}$ and $\varepsilon_{\mathrm{m}} \approx-\varepsilon_{\mathrm{p}}$ $/ 2$ are dielectric function of NS and embedding medium respectively 
Citation: Khosroshahi ME, Asemani M, Khoshkenar P (2019) Laser Auto Fluorescence and Dye-enhanced Spectroscopic Detection of Normal and Cancerous Human Lung Cell Lines and Plasmonic Photothermal Heating. J Nanomed Nanotechnol 10: 525. doi: 10.4172/21577439.1000525
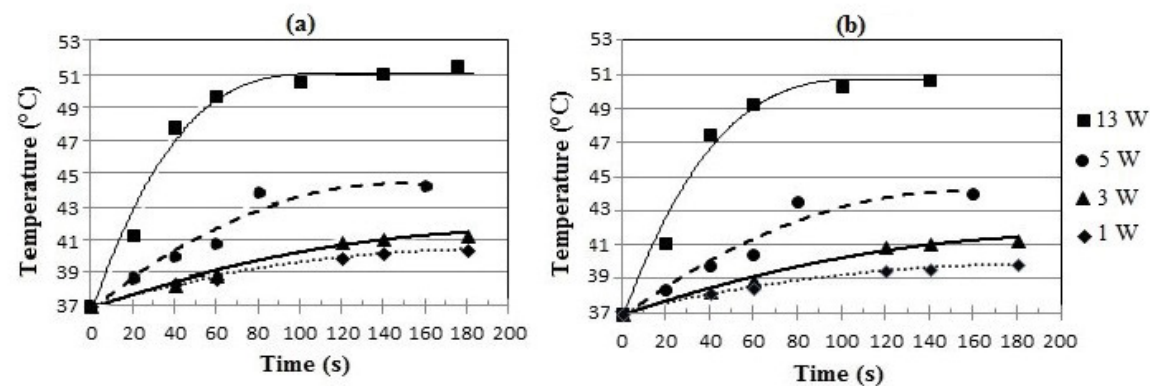

(c)
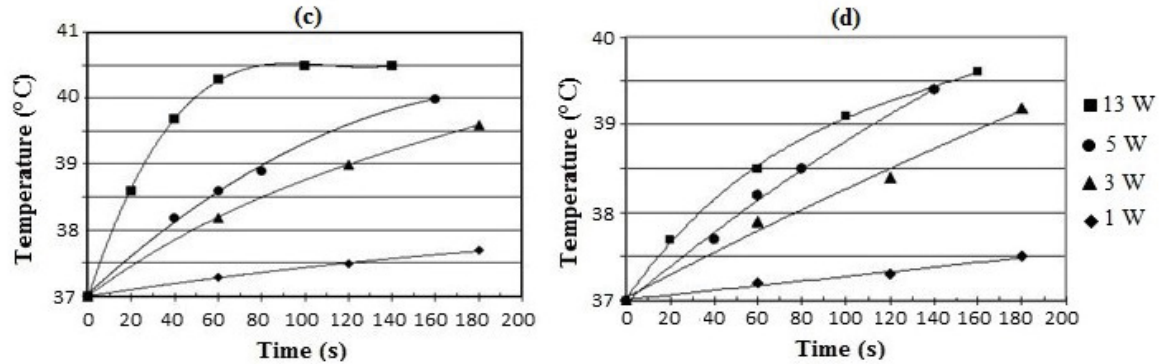

(e)
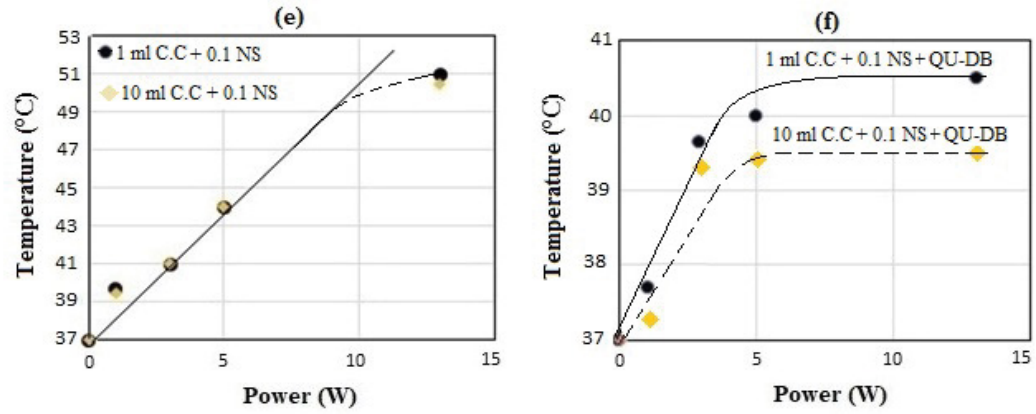

Figure 8: Variation of temperature with irradiation time for (a) $0.1 \mathrm{mg} / \mathrm{mL} \mathrm{NS}+1 \mathrm{ml} \mathrm{C.C} \mathrm{(S3),} 0.1 \mathrm{mg} / \mathrm{mL} \mathrm{NS}+10 \mathrm{ml}$ C.C (S4), (c) $0.1 \mathrm{mg} / \mathrm{mL} \mathrm{NS}+1 \mathrm{ml} \mathrm{C.C}$ + QU-DB cells (S5), (d) $0.1 \mathrm{mg} / \mathrm{mL} \mathrm{NS}+10 \mathrm{ml} \mathrm{C.C} \mathrm{+} \mathrm{QU-DB} \mathrm{cells} \mathrm{(S6).} \mathrm{Behaviour} \mathrm{of} \mathrm{temperature} \mathrm{with} \mathrm{power} \mathrm{for} \mathrm{(e)} \mathrm{S3} \mathrm{and} \mathrm{S4} \mathrm{and} \mathrm{(f)} \mathrm{S5} \mathrm{and} \mathrm{S6} \mathrm{at} \mathrm{different}$ concentrations.

and $\alpha_{\mathrm{p}}$ is absorption coefficient of NS. The real part, $\varepsilon_{\mathrm{r}}=\left(\mathrm{n}_{\mathrm{p}}{ }^{2}-\mathrm{k}_{\mathrm{e}}{ }^{2}\right) \approx-7.6$, where $\mathrm{n}_{\mathrm{p}}$ is the real refractive index of NS and the imaginary part, i $\varepsilon_{\mathrm{i}}$ $=2 \mathrm{n}_{\mathrm{p}} \mathrm{k}_{\mathrm{e}} \approx 1.56$, which quantifies the relative phase shift of the induced polarization with respect to the external field and includes losses such as ohmic heat loss. Thus, $\mathrm{k}_{\mathrm{e}} \approx 2.78$ and $\alpha_{\mathrm{p}}=4 \pi \mathrm{k}_{\mathrm{e}} / \lambda \approx 4.3 \times 10^{5} \mathrm{~cm}^{-1}$ are determined for gold at $800 \mathrm{~nm}$ which are comparable with Etchegoin et al. [38].

Despite time dependence of the laser oscillatory field is, it is assumed that it does not vary spatially over the NS diameter where it is much smaller than the laser wavelength. Therefore, the electric field of the laser is assumed to have a constant component where the wave is traveling in the $\mathrm{z}$ direction. At the surface between air and water (e.g., cell culture dish), part of the incident field will be reflected from the interface, and partly will be transmitted into water medium. The incident electric field in the embedding medium $\mathrm{E}_{\mathrm{m}}$ is written [39-41]:

$$
E_{m}=\frac{2 Z_{m}}{Z_{a}+Z_{m}} E_{L} e^{-\alpha d}
$$

where $\mathrm{Z}_{\mathrm{m}}$, and $\mathrm{Z}_{\mathrm{a}}$ are respectively the intrinsic impedances $\left(\frac{\mu}{\varepsilon}\right)$ of medium, air and $E_{L}=\left(2 I \mu_{0} \varepsilon c\right)^{1 / 2}$ is the laser electric field where $I$ is the incident laser power density, $\mu_{0}$ and $\varepsilon$ are permeability and permittivity of the medium, $c$ is velocity of light in vacuum, $\alpha$ is the attenuation coefficient of electromagnetic wave in medium and $d$ is the distance travelled within the medium. The average power density associated with the transmitted field in embedding medium is given by [40]:

$$
\langle I\rangle=\frac{2\left|E_{m}\right|^{2}}{Z_{L}}
$$

where $\mathrm{Z}=120 \pi / \mathrm{n}$ is laser field impedance and $\mathrm{n}$ are the real part of water refractive index. Now, the total extinction cross section of a NS is

$$
\begin{aligned}
& \sigma_{\text {ext }}=\sigma_{\text {abs }+} \sigma_{\text {sca }} \\
& \sigma_{e x t}=\frac{9 V \varepsilon_{m}^{3 / 2}}{c}\left(\frac{\omega \varepsilon_{i}(\omega)}{\left[\varepsilon_{r}(\omega)+2 \varepsilon_{m}\right]^{2}+\varepsilon_{i}(\omega)^{2}}\right) \\
& \sigma_{s c a}=\frac{8 \pi^{3}}{3 \varepsilon_{0}^{2} \lambda^{4}}|\alpha|^{2}
\end{aligned}
$$


Citation: Khosroshahi ME, Asemani M, Khoshkenar P (2019) Laser Auto Fluorescence and Dye-enhanced Spectroscopic Detection of Normal and Cancerous Human Lung Cell Lines and Plasmonic Photothermal Heating. J Nanomed Nanotechnol 10: 525. doi: 10.4172/21577439.1000525

(a)

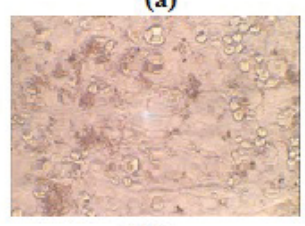

1W

(al)

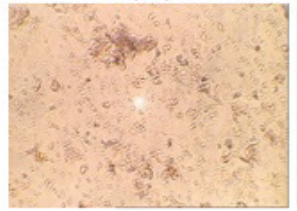

1W (b)

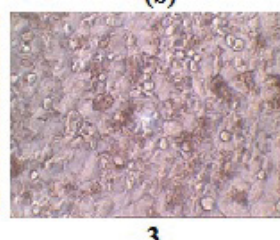

(b1)

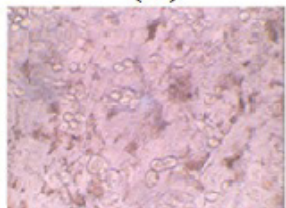

3 (c)

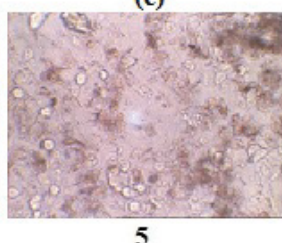

(c1)

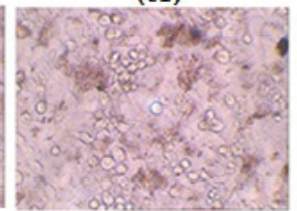

5 (d)

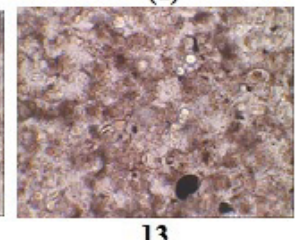

(dl)

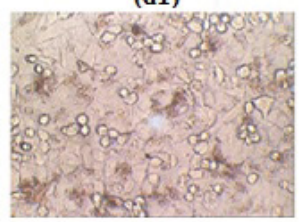

13

Figure 9: Optical microscope images of S5 at different laser power. The top raw illustrates the photothermal effect at laser focal points with similar corresponding effect at radial distances greater than laser spot size shown in the bottom row. The heating effects become more evident seen as darker brown regions when laser power increases.

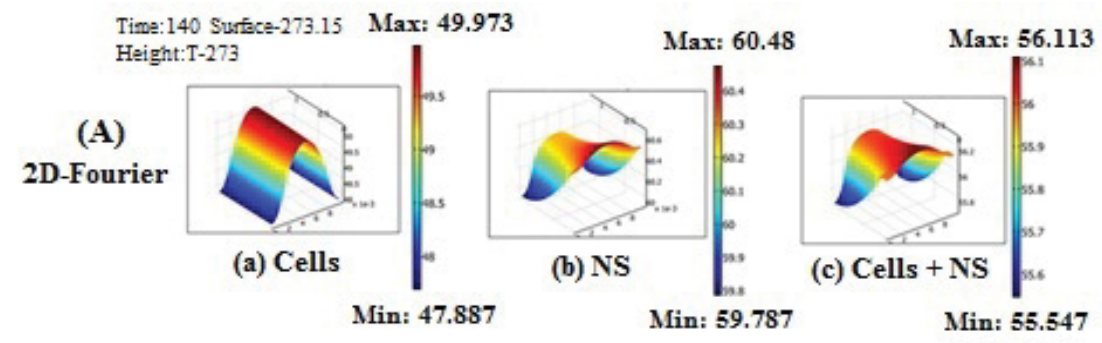

(B)

2D-Non-Fourier
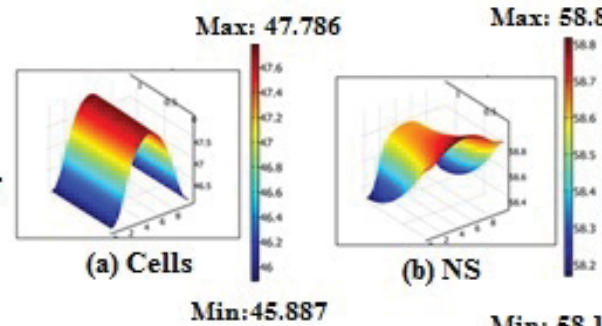

(b) NS

Min: $\mathbf{5 8 . 1 6 9}$

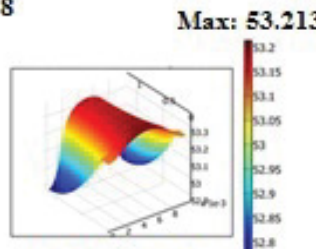

(c) Cells + NS

Min: $\mathbf{5 2 . 7 3 2}$

Figure 10: Fourier and non-Fourier simulation of heat transfer in (a) QU-DB cells, (b) $0.1 \mathrm{mg} / \mathrm{mL} \mathrm{NS}$ and (c) and $0.1 \mathrm{mg} / \mathrm{mL} \mathrm{NS}+1 \mathrm{ml}$ C.C + QU-DB cells (S5). The non-Fourier simulation results are relatively closer to the experimental results compared to Fourier model.

$$
\sigma_{s c a}=\frac{8 \pi^{3}}{3 \varepsilon_{0}^{2} \lambda^{4}}|\alpha|^{2}
$$

where $\mathrm{V}$ is the particle volume, $\omega$ is the angular frequency of the exciting light, $c$ is the velocity of light, $\lambda$ is the laser wavelength and $\varepsilon_{0}=8.85 \times 10^{-12} \mathrm{Fm}^{-1}$ is the free space permeability and $\operatorname{Im}(\alpha)$ is the imaginary part of complex polarizability of particle $(\alpha)$.

$$
\alpha=\frac{\left(\varepsilon_{s}-\varepsilon_{m}\right)\left(\varepsilon_{c}+2 \varepsilon_{s}\right)+\left(R_{c} / R_{s}\right)^{3}\left(\varepsilon_{c}-\varepsilon_{s}\right)\left(\varepsilon_{m}+2 \varepsilon_{s}\right)}{\left(\varepsilon_{s}+2 \varepsilon_{m}\right)\left(\varepsilon_{c}+2 \varepsilon_{s}\right)+\left(R_{c} / R_{s}\right)^{3}\left(\varepsilon_{c}-\varepsilon_{s}\right)\left(2 \varepsilon_{m}-\varepsilon_{m}\right)} 4 \pi \varepsilon_{0} R_{s}^{3}
$$

where $\varepsilon_{\mathrm{s}}, \varepsilon_{\mathrm{c}}, \varepsilon_{\mathrm{m}}$ are dielectric functions of shell, core and embedding medium respectively and $\mathrm{Rs}$ and $\mathrm{R}_{\mathrm{c}}$ are the corresponding core and shell radii. Substituting eq. (11) in (9) gives [42,43]:

$$
\begin{aligned}
& \sigma_{a b s}=\frac{8 \pi^{2} \sqrt{\varepsilon_{m}}}{\lambda} R_{p}^{3}\left(\frac{\varepsilon_{s} \varepsilon_{a}-\varepsilon_{m} \varepsilon_{b}}{\varepsilon_{s} \varepsilon_{a}+2 \varepsilon_{m} \varepsilon_{b}}\right) \\
& \varepsilon_{a}=\varepsilon_{c}(3-2 P)+2 \varepsilon_{s} P \\
& \varepsilon_{b}=\varepsilon_{c} P+\varepsilon_{s}(3-P) \\
& P=1-\left(R_{c} / R_{s}\right)^{3}
\end{aligned}
$$

For simplicity and close approximation, the embedding medium i.e, CCM is assumed water with a dielectric function $\varepsilon_{\mathrm{m}}=2.5$ for the real part of NIR laser at $3.7 \times 10^{14} \mathrm{~Hz}$ [43]. Substituting the values of $\left(\varepsilon_{\mathrm{m}}\right)^{1 / 2}$ $\approx 1.58, \varepsilon_{\mathrm{c}} \approx 8 \times 10^{-11}, \varepsilon_{\mathrm{s}} \approx-6, \mathrm{P}=-1.92, \varepsilon_{\mathrm{a}} \approx 23, \varepsilon_{\mathrm{b}} \approx-29.52$ and $\mathrm{R}_{\mathrm{p}} \approx 42.5$ 
Citation: Khosroshahi ME, Asemani M, Khoshkenar P (2019) Laser Auto Fluorescence and Dye-enhanced Spectroscopic Detection of Normal and Cancerous Human Lung Cell Lines and Plasmonic Photothermal Heating. J Nanomed Nanotechnol 10: 525. doi: 10.4172/21577439.1000525

Page 11 of 13

nm in eq. (12) yield $\sigma_{a b s} \approx 5.40 \times 10^{-15} \mathrm{~m}^{2}$ which is comparable with the results obtained by Jain et al. [44], Pustovalov [45] and Khosroshahi et al. $[46,47]$ and the particle absorption efficiency, $\eta_{\mathrm{abs}}$ is

$$
\eta_{a b s}=\frac{\sigma_{a b s}}{\pi R_{p}^{2}} \approx 95 \times 10^{-2}
$$

Initially, the absorption of laser energy by NSs produces a heating effect which rapidly is equilibrated within the NS ensemble. Subsequently, the heat is transferred from the NSs to the surrounding medium (cells and CCM) via non-radiative relaxation. The characteristic thermal relaxation time for NS is [48]

$$
\tau_{r}=\frac{\rho_{p} c_{p} R_{p}^{2}}{3 K_{p}}
$$

where $\rho_{\mathrm{p}} \approx 19.3 \mathrm{~g} \mathrm{~cm}^{-3}$, and $\mathrm{c}_{\mathrm{p}} \approx 0.13 \mathrm{~J} \mathrm{~g}^{-1} \mathrm{c}^{-1}, \mathrm{~K}_{\mathrm{p}} \approx\left(\mathrm{D}_{\mathrm{p}} \rho_{\mathrm{p}} \mathrm{c}_{\mathrm{p}}\right) \approx 301 \mathrm{~W}$ $\mathrm{m}^{-1} \mathrm{c}^{-1}$ are the density, specific heat capacity, thermal conductivity and $\mathrm{D}_{\mathrm{p}} \approx 1.2 \times 10^{-4} \mathrm{~m}^{2} \mathrm{~s}^{-1}[48]$ is the thermal diffusivity of NS. By substituting the above values in eq. (17), it yields $\tau_{\mathrm{r}} \approx 5$ ps which is much smaller than the laser irradiation time particularly when it is continuous wave thus, there is a non-adiabatic case where the heat generated is not confined and will be diffused between NSs and cell environment. Also, since the parabolic Fourier heat conduction leads to inaccuracies at extremely short time scales for at very small length scales therefore, in the absence of phase transformations, heat transfer in a system with NS thermal sources is described by the non-Fourier hyperbolic heat conduction equation

$$
\rho c \tau_{r}\left(\frac{\partial^{2} T(r, t)}{\partial t^{2}}\right)+\rho c\left(\frac{\partial^{2} T(r, t)}{\partial t}\right)=K_{m} \nabla^{2} T+Q(r, t)
$$

where $T(r, t)$ is temperature and $Q(r, t)$ is the heating source.

However, for the purpose of comparison, the results of both Fourier and non-Fourier heat conduction simulation are presented. The heat is distributed within the medium with a finite velocity:

$$
V_{d}=\sqrt{\frac{K_{m}}{\rho_{m} c_{m}}}
$$

The total amount of heat produced is $\mathrm{Q}_{\mathrm{T}}=\mathrm{Q}_{\mathrm{m}}+\mathrm{Q}_{\mathrm{p}}$, where $\mathrm{Q}_{\mathrm{m}}$ and $\mathrm{Q}_{\mathrm{p}}$ represent the components produced by medium and gold NSs, respectively. In our case, the approximation $2 \pi R_{p} / \lambda(\approx 0.33)<1$ holds, so it is assumed that each NS is quasi-transparent to the incident light and $\mathrm{Q}_{\mathrm{p}}$ is constant across each nanoparticle. For a single Au NS exposed to a laser beam the generated power is $\mathrm{P}=\mathrm{I}_{0} \sigma_{\text {abs }}$ and $\mathrm{Q}_{\mathrm{p}}=\mathrm{P} / \mathrm{V}_{\mathrm{g}}$ where $V_{p}$ is the volume of the NS. The heat source is derived from the heat power density $h_{\rho}(r)=\int_{v} h_{\rho}(r) d^{3} r$, where the integral is over the NS volume $V_{p}$. To calculate $Q_{p}(r, t)$, we assume the size of a NS is smaller than the laser wavelength (i.e., $85 \mathrm{~nm}<<808 \mathrm{~nm}$ ) so that electrons inside the NSs respond collectively to the applied electric field of the laser radiation, $E_{m}(r, t)=\frac{3 \varepsilon_{m}}{\varepsilon_{P}+2 \varepsilon_{m}}$

Therefore, the heat generated for N number of NSs is [49]:

$$
Q=<j(r, t) \cdot E_{m}(r, t)>=\frac{2 \pi N n_{m}\left|E_{m}\right|^{2} \sqrt{\varepsilon_{m}}}{15 \lambda} \operatorname{Im}\left(\frac{\varepsilon_{s} \varepsilon_{a}-\varepsilon_{m} \varepsilon_{b}}{\varepsilon_{s} \varepsilon_{a}+\varepsilon_{m} \varepsilon_{b}}\right)
$$

where $j(r, t)$ is the current density inside the metallic NP and the heat generated is thus directly proportional to the square modulus of the NP electric field [50]. The power is given by

$$
\begin{gathered}
P=I \sigma_{a b s}=4 \pi R^{3} K_{p} \frac{C \varepsilon_{m}}{2}|E|^{2} \operatorname{Im}\left(\frac{\varepsilon_{s} \varepsilon_{a}-\varepsilon_{m} \varepsilon_{b}}{\varepsilon_{s} \varepsilon_{a}+\varepsilon_{m} \varepsilon_{b}}\right) \\
P=4 \pi R^{3} K_{p} \frac{C \varepsilon_{m}}{2}\left|E_{m}\right|^{2}\left|\frac{3 \varepsilon_{\mathrm{m}}}{\varepsilon_{\mathrm{p}}+2 \varepsilon_{\mathrm{m}}}\right|^{2} \operatorname{Im}\left(\frac{\varepsilon_{s} \varepsilon_{a}-\varepsilon_{m} \varepsilon_{b}}{\varepsilon_{s} \varepsilon_{a}+\varepsilon_{m} \varepsilon_{b}}\right)
\end{gathered}
$$

Under a non-adiabatic condition where the optical penetration depth $\alpha^{-1}<<$ thermal diffusion depth $\mathrm{X}_{\mathrm{T}} \approx\left(4 \mathrm{D}_{\mathrm{p}} \mathrm{t}\right)^{1 / 2}$ or the irradiation time, $t>$ characteristic time, $t_{c}$ then in the steady-state regime, the local temperature profile around a NP (i.e., $r \geq R_{p}$ ) is described by the temperature increase $\Delta \mathrm{T}$ given by a Coulomb potential outside the NS [51].

$$
\Delta T(r)=\frac{I K_{p} R_{p}^{2}}{K_{m}} \operatorname{Im}\left(\frac{\varepsilon_{s} \varepsilon_{a}-\varepsilon_{m} \varepsilon_{b}}{\varepsilon_{s} \varepsilon_{a}+\varepsilon_{m} \varepsilon_{b}}\right) \text { at } \mathrm{r} \geq \mathrm{R}_{\mathrm{p}}
$$

Thus, the temperature increase at the surface of NS (i.e., at $r=\mathrm{R}_{\mathrm{p}}$ )

$$
\Delta T(r)=\frac{I K_{p} R_{p}^{2}}{K_{m}} \operatorname{Im}\left(\frac{\varepsilon_{s} \varepsilon_{a}-\varepsilon_{m} \varepsilon_{b}}{\varepsilon_{s} \varepsilon_{a}+\varepsilon_{m} \varepsilon_{b}}\right)
$$

The maximum temperature $T_{\max }$ of spherical NS at the end of laser irradiation time $t_{e}$ under constant radiation power density $\mathrm{I}_{0}$ is

$$
T_{\max }=T_{i}+\frac{I_{0} \eta_{a b s} R_{c}}{4 K_{m}}\left[1-\exp \left(-\frac{3 K_{m} t_{e}}{c_{c} \rho_{c} r_{c}^{2}}\right)\right]
$$

The results indicate that the concentration of NS have a significant effect on the amount of heat generated at given power density. For a NS, the efficiency parameter which represents the efficiency of transformation of absorbed optical energy into thermal energy is defined as:

$$
\frac{\Delta T_{0}}{I_{0}}=\frac{\eta_{a b s} R_{s}}{4 K_{m}} \times\left[1-\exp \left(-\frac{3 K_{m} t_{e}}{r_{1}^{2}\left(c_{c} \rho_{c} R_{c}^{3}+c_{s} \rho_{s}\left(1-R_{c}^{3} / R_{s}^{3}\right)\right.}\right)\right]
$$

According to the equation (25) for $t_{e}>\tau_{r}$ such in our case (or if it is a pulse laser, $\tau_{p} \gg \tau_{r}$ ) heating

of both the particle and the surrounding medium occurs and the heat conduction occurs during the time exposure which will determine the maximal value of temperature. If, however, $\tau_{\mathrm{p}}<<\tau_{\mathrm{r}}$ then

the laser energy can be confined within the nanoparticle and the heat loss from NPs can be ignored.

In our case, $\Delta \mathrm{T}_{0} / \mathrm{I}_{0}$ corresponds to about $12 \%$ and by increasing the power density, the temperature increased faster and higher according to

$$
T(r, t)=\alpha_{p} \int_{0}^{t} \frac{I d t}{\rho_{p} c_{p}}
$$

Optical microscopy showed that most cells have become circular due to induced thermal stress. It is assumed that most of the Au NSs are accumulated at the center of the wells, where the laser beam was focused. This may be due to the movement of NSs in the direction of the force gradient towards the center of the beam [52,53]. The percentage of damaged cells and NSs are expected to decrease with radial distance from the center of the beam. The results also indicate that apoptosis increases with increase of power density confirming the 
Citation: Khosroshahi ME, Asemani M, Khoshkenar P (2019) Laser Auto Fluorescence and Dye-enhanced Spectroscopic Detection of Normal and Cancerous Human Lung Cell Lines and Plasmonic Photothermal Heating. J Nanomed Nanotechnol 10: 525. doi: 10.4172/21577439.1000525

Page 12 of 13

fact that temperature variation critically governs the quality of and the degree of laser-hyperthermia. In case of thermal application of laser, the therapeutic effect is due to thermal denaturation or inactivation of proteins and enzymes. The induced damage at time $t$ is a temperaturedependent process expressed by Arrhenius equation

$$
\Omega(t)=\int_{0}^{t} \beta \cdot d t
$$

Where $\beta$ is reaction rate and Birngruber [52] showed that it can be expressed in terms of thermo-chemical characteristics of the molecular system

$$
\Omega(t)=\int_{t_{i}}^{t_{f}} \mathrm{e}^{-\left[\frac{\Delta E}{R \cdot T}\right]} d t
$$

where $\Delta \mathrm{E}$ is the activation energy $\left(\mathrm{J} \mathrm{mol}^{-1}\right), \mathrm{R}$ is the molar gas constant $\left(8.3 \mathrm{~J} \mathrm{~mol}^{-1}\right)$ and $\mathrm{T}$ is temperature $(\mathrm{K})$, hence

$$
\frac{d \Omega}{d t}=A \cdot \mathrm{e}^{-\left[\frac{\Delta E}{R \cdot T}\right]}
$$

where $A\left(S^{-1}\right)$ is frequency factor.

$$
A=\frac{K T}{h} \mathrm{e}^{-\left[\frac{\Delta S}{R}\right]}
$$

and $\mathrm{K}, \mathrm{h}$ and $\Delta \mathrm{S}$ are the Boltzmann constant $\left(1.38 \times 10^{-23} \mathrm{JK}^{-1}\right)$ Planck constant $\left(6.63 \times 10^{-34} \mathrm{Js}\right)$ and entropy. Therefore, one can estimate the end point damage $\Omega$ inside the irradiated area using the Arrhenius integral assuming that damage is due to thermal denaturation of proteins [54]

$$
\Omega(t)=\operatorname{In} \frac{C_{0}}{C_{t}}=\int_{t_{i}}^{t_{f}} \frac{k T}{h} \mathrm{e}^{-\left[\frac{\Delta S}{R}\right]} \cdot \mathrm{e}^{-\left[\frac{\Delta H}{R T}\right]} d t
$$

where Co is the initial concentration of the native state (undamaged) tissue constituent molecules, $\mathrm{Ct}$ is the concentration of undamaged molecules after time $(\mathrm{t})$ and $\Delta \mathrm{H}$ is enthalpy. Conventionally, $\Omega(\mathrm{t})=$ 0 implies no tissue damage at all, $\Omega(\mathrm{t})=1$ means most (i.e., $63 \%$ ) of the tissue is damaged and $\Omega(\mathrm{t})>1$ represents a complete irreversible damage. In our case, this likely occurs after $5 \mathrm{~W}$ and beyond where the curve becomes irreversible. It is noteworthy that on the microscale it can be assumed that NSs are totally embedded within the CCM and cell matrix and are small enough to have a uniform steady-state temperature equal to the surrounding matrix temperature owing to fast heat transfer and thermalization time. However, on a larger scale, for example after some agglomeration, the matrix temperature may be different due to possible thermal overlapping of a larger fraction of NSs and clustering. Since, NSs are dispersed inside a static colloidal medium, their distribution within cell culture dish can be considered as Brownian motion. Therefore, assuming, $\Psi\left(r^{\prime}\right)=d^{3} r^{\prime} \rho\left(r^{\prime}\right)$ where $\Psi\left(r^{\prime}\right)$ is the probability of finding a NS at a distance $r^{\prime}$ in a volume $d^{3} r^{\prime}$, and $\rho\left(r^{\prime}\right)$ is the density distribution of NSs, a function which decays according to the spatially damped radial function [54]

$$
\rho(r)=\frac{N_{p} R_{p}}{R_{L}} \frac{1}{4 \pi R_{L}^{2}} \frac{e^{-r^{\prime} / R_{L}}}{r^{\prime}}
$$

where $R_{L}$ is the radius of cell. It is suggested that at early times where the NSs are likely more dispersed in the base medium will be displaced faster and freely (i.e., lighter) and when they gradually become agglomerated they become less mobile (i.e., heavier) with lower degree of freedom as the morphology of a fractal aggregate is characterized by its fractal dimension $\Phi_{f}$, which relates the mass of an aggregate $\left(M_{g}\right)$ to its radius of gyration $\left(R_{g}\right)$ as $M_{g} \propto R_{g}^{-\Phi f}$. Therefore, the diffusion of nanoparticle agglomeration, which depends upon their mass and morphology, plays an important role in the agglomeration kinetics and the final cluster size distribution.

\section{Conclusion}

The results show that LIFS and plasmonic nanoshells have the potential to be utilized for differentiating and photothermal apoptosis of cancerous cells. The intensity ratio and the shape factor are appropriate indicators of normal and cancerous cells. The degree of red shift in peak observed for the cancerous cells depends on the cellular state. Highest temperatures were achieved for $(\mathrm{S} 3, \mathrm{~S} 4)$ than $(\mathrm{S} 5, \mathrm{~S} 6)$ respectively due to absence of cells. A non-linear thermal response was observed for both cell culture concentrations containing cells as a function of laser power. The photothermal effect gradually became significant at higher laser powers. The spatial and temporal distribution of plasmonic nanoparticles, thermal overlapping, agglomeration and clustering are all important factors in defining the final laser hyperthermia effect.

\section{References}

1. Sokolov K, Aaron J, Hu B, Nida D, Gillenwater A et al. (2003) Optical systems for in-vivo molecular imaging of cancer. Technol Cancer Res Treat 2: 491-504.

2. Ramalingam S, Owonikoko T, Khuri FR (2011) Lung cancer: new biological insights and recen therapeutic advances. CA Cancer J for Clin 61: 91-112.

3. http://www.aicr.org/enews/2018/01-january/

4. Xing L, Todd NW, Yu L, Fang H, Jiang F (2010) Early detection of squamous cell lung cancer in sputum by a panel of microrna markers. Mod Pathol 23 . 1157-1164.

5. Alfano R, Tang G, Pradhan A, Lam W, Choy D, et al. (1987) Fluorescence spectra from cancerous and normal human breast and lung tissues. IEEE J Q Elect QE 23: 1806-1811.

6. Khosroshahi ME, Rahmani M (2012) Detection and evaluation of normal and malignant cells using laser-induced fluorescence spectroscopy. J Fluo 22: 281-288.

7. Judy R, Keating J, Dejesus E, Jiang JX, Okusanya OT, et al. (2015) Quantification of tumor fluorescence during intraoperative optical cancer imaging. Sci Rep 5: 1-11.

8. Khosroshahi ME, Tajabadi M (2016) Characterization and cellular fluorescence microscopy of superparamagnetic nanoparticles functionalized with third generation nanomolecular dendrimers: In-vitro cytotoxicity and uptake study. J Nanomater Mol Nanotechnol 5: 1-11.

9. Lakowicz JR (1999) Principle of Fluorescence spectroscopy. (2 ${ }^{\text {nd }}$ edtn), Kluwer Academic, Plenum, New York, USA.

10. Haringsma H, Tytgat G (1999) Fluorescence and autofluorescence. Baillier's Clinc Gastroent 13: 1-10.

11. Anidjar M, Cussenot O, Avrillier S, Ettori D, Teillac P, et al. (1998) The role of laser-induced autofluorescence spectroscopy in bladder tumor detection. Dependence on the excitation wavelength. Annals New York Acad Sci 838 130-142.

12. Fang Q, Papaioannou T, Jo J (2004) Time-domain laser-induced fluorescence spectroscopy apparatus for clinical diagnostics. Rev Sci Inst 75: 151-162.

13. Gindy M, Prud'homme R (2009) Multifunctional nanoparticles for imaging delivery and targeting cancer therapy. Expert Opin Drug Deliv 6: 865-877.

14. Shixian L, Zhaohui T, Mingqiang Li, Xiangyu Zhang, Yanwei Teng, et al. (2014) Co-delivery of doxorubicin and paclitaxel by PEG-polyypeptide nanovehicle for the treatment of non-small cell lung cancer. Biomat 35: 6118-6129.

15. Khosroshahi ME, Ghazanfari L, Khoshkenar P (2014) Experimental validation 
Citation: Khosroshahi ME, Asemani M, Khoshkenar P (2019) Laser Auto Fluorescence and Dye-enhanced Spectroscopic Detection of Normal and Cancerous Human Lung Cell Lines and Plasmonic Photothermal Heating. J Nanomed Nanotechnol 10: 525. doi: 10.4172/21577439.1000525

Page 13 of 13

and simulation of Fourier and non-Fourier heat transfer equation during laser nano - phototherapy of lung cancer cells: An in vitro assay. J Mod Phys 5: 2125-2141.

16. Khosroshahi ME, Ghazanfari L, Hassannejad Z, Lenhert S (2015) In-vitro application of doxorubicin loaded magnetoplasmonic thermosensitive liposomes for laser hyperthermia and chemotherapy of breast cancer. Nanomed Nanotech 6: 1-11.

17. Hung-Yen L, Kamal M, Najmunnisa N (2016) Nanoparticle-based targeted gene therapy for lung cancer. Am J Can Res 6: 1118-1134.

18. Farhane Z, Bonnier F, Maher M, Bryant J, Casey A, et al. (2017) Differentiating response of lung cancer cell lines to doxorubicin exposure: In Vitro Raman microscopy, oxidative stress and bcl-2 protein expression. J Biophotonics 10 $151-165$

19. Khosroshahi ME, Hassannejad Z, Firouzi M, Arshi A (2015) Nanoshellmediated targeted hotothermal therapy of HER2 human breast cancer cells using pulsed and continuous wave lasers: an in vitro study. Laser Med Sci 30: 1913-1922.

20. Park S, Jaewon L, Taeksu L, Bae SB, Kang B, et al. (2015) Comparative hyperthermia effect of silics-gold nanoshells with different surface covrage of gold clusters on epithelial tumor cells. Int J Nanomed 10: 261-271.

21. Khosroshahi ME, Taghizadeh Khoi N (2014) Comparison of blue wavelengths and scan velocity effects on detection of enamel surface caries using steadystate laser-induced autofluorescence spectroscopy. J Appl Spect 81: 347-354.

22. Khosroshahi ME, Asemani M (2017) Synthesis, Characterization and Imaging of Fluorescine Isothiocyanate Conjugated Magnetite Nanoparticles in MCF 7 Breast Cancer Cell Lines. Int J Nanomat Nanotech Nanomed 3: 44-50.

23. Khosroshahi ME, Ghazanfari L (2012) Physicochemical characterization of Fe3O4/SiO2/Au multilayer nanostructure. Mat Chem Phys 133: 55-62.

24. Alfano R, Tang G, Pradhan A, Lam W, Choy D, et al (1986) Fluorescence spectra from cancerous and normal human breast and lung tissues. IEEE J Q Elect 23: 1806-1811.

25. Haringsma J, Tytgat GN (1999) Fluorescence and autofluorescence. Baillieres Best Pract Res Clin Gastroenterol 13: 1-10.

26. Colasanti A, Kisslinger A, Fabbrocini G, Liuzzi R, Quarto M, et al. (2000) MS-2 fibrosarcoma characterization by laser induced autofluorescence. Lasers Surg Med 26: 441-448.

27. Tang GC, Pradhan A, Alfano R (1989) Spectroscopic differences between human cancer and normal lung and breast tissues. Lasers Surg Med 9: 290-295.

28. Kusunoki Y, Imamura F, Uda H, Mano M, Horai T, et al. (2000) Early detection of lung cancer with laser-induced fluorescence endoscopy and spectrofluorometry. Chest J 118: 1776-1782.

29. Palmer GM, Keely P, Breslin T, Ramanujam N (2003) Autofluorescence spectroscopy of normal and carcinoma human breast cell lines. Photochem Photobiol 78: 462-469.

30. Pesce A, Rosen C, Pasby T (1971) Fluorescence spectroscopy: An introduction for biology and medicine. 247 New York, USA.

31. Hung J, Lam S, LeRiche JC, Palcic B (1991) Autofluorescence of normal and malignant bronchial tissue. Laser Surg 11: 99-105.

32. Joanitti G, Azevedo R, Freitas S (2010) Apoptosis and lysosome membrane permeabilization induction on breast cancer cells by an anticarcinogenic Bowman-Birk protease inhibitor from Vigna unguiculata seeds. Cancer Lett 293: 73-81.

33. Kong G, Braun R, Dewhirst MW (2000) Hyperthermia enables tumor-specific nanoparticle delivery: effect of particle size. Cancer Res 60: 4440-4445.

34. Lee Y, Wong KT, Tan J, Toh P, Mao Y et al. (2009) Overexpression of heat shock proteins (HSPs) in $\mathrm{CHO}$ cells for extended culture viability and improved recombinant protein production. J Biotech 143: 34-43.

35. Nikfarjam M, Muralidharan V, Christophi C (2005) Mechanisms of focal heat destruction of liver tumors. J Surg Res 127: 208-223.

36. Clark A, Robins H, Vorpahl J, Yatvin M (1983) Structural changes in murine cancerassociated with hyperthermia and lidocaine. Cancer Res 43: 1716-1723.

37. Soto-Cerrato V, Montaner B, Martinell M, Vilaseca M, Giralt E, et al. (2005) Cell cycle arrest and proapoptotic effects of the anticancer cyclodepsipeptide serratamolide (AT514) are dependent of p53 status in breast cancer cells. Biochem Pharm 71: 32-41.

38. Etchegoin P, Le Ru E, Meyer M (2006) An analytic model for the optical properties of gold. J Chem Phys 125: 164705.

39. Balanis C (2012) Advanced Engineering Electromagnetics, John Wiley \& Sons, New York, USA.

40. Jiang S, Georgakopoulos S (2011) Electromagnetic wave propagation into fresh water. J Electromag Anal Appl 3: 261-266.

41. Van de Hulst H (1981) Light Scattering by Small Particles. Dover, New York, USA.

42. Yan Sh, Wang Y, Wen T, Zhu J (2006) A study of the opticalabsorption properties of dielectric-mediated gold nanoshells. Physica E 33: 139-143.

43. Dagastine R, Preve D, White $L$ (2000) The dielectric function for water and its application to van der Waals forces. L Colloid Interf Sci 231: 351-358.

44. Jain PK, Lee KS, El-Sayed IH, El-Sayed MA (2006) Calculated absorption and scattering properties of gold nanoparticles of different shape, and composition: applications in biomedical imaging and biomedicine. J Phys Chem B 110: 7238-7248.

45. Pustovalov VK, Astafyeva LG, Galanzha E, Zharov VP (2010) Thermo-optica analysis and selection of the properties of absorbing nanoparticles for laser applications in cancer nanotechnology. Cancer Nanotechnol 1: 35-46.

46. Khosroshahi ME, Mandelis A, Lashkari B (2015) Frequency-domain photothermoacoustic and ultrasonic imaging of blood and opto-thermal effects of plasmonic nanoparticle concentrations. J Biomed Opt 20: 076009.

47. KhosroshahiM E, Mandelis A (2015) Combined photoacoustic ultrasound and beam deflection signal monitoring of gold nanoparticle agglomerate concentrations in tissue phantoms using a pulsed Nd: YAG laser. Int J Thermophys 36: 880 .

48. Hossain M, Kitahama Y, Huang GG, Han X, Ozaki Y (2009) Surface-enhanced Raman scattering: realization of localized surface Plasmon resonance using unique substrates and methods. Ana Bioanal Chem 394: 1747-1760.

49. Roggan A, Friebel M, Do Rschel K, Hahn A, Mu Ller G (1999) Optical propertie of circulating human blood in the wavelength range $400-2500 \mathrm{~nm}$. J Biomed Opt 4: 36-46.

50. Govorov A, Zhang W, Skeini T, Richardson H, Lee J, et al. (2006) Gold nanoparticles as heaters and actuators: melting and collective plasmon resonances. Nanoscale Res Lett 1: 84-90.

51. Kurian A, Kumar R, George S (2009) Thermal characterization of nanofluids using laser induced thermal lens technique. Proc SPIE 7393: 73930U.

52. Birngruber $\mathrm{R}$ (1979) Thermal modelling of biological tissues. Hillenkamp, Pratesi \& Sacchi, Plenum Press, New York, USA.

53. Rastgar S, Kim B, Jacques L (1992) Role of temperature dependence of optical properties in laser irradiation of biological tissues. SPIE 1646: 228-231.

54. Fals B, Senoudi A, Boussaid A (2011) Heating of bio logical tissues by nanoparticles: Effects of particles size and distribution. J Biomat Nanobiotech 2. $49-54$ 